Article

\title{
Biocontrol of Invasive Conical Snails by the Parasitoid Fly Sarcophaga villeneuveana in South Australia 20 Years after Release
}

\author{
Kate A. Muirhead ${ }^{1,2, *(D)}$ and Kym D. Perry ${ }^{1,2, *(D)}$ \\ 1 South Australian Research and Development Institute, Adelaide, SA 5001, Australia \\ 2 School of Agriculture, Food and Wine, The University of Adelaide, Adelaide, SA 5005, Australia \\ * Correspondence: kate.muirhead@sa.gov.au (K.A.M.); kym.perry@sa.gov.au (K.D.P.)
}

Citation: Muirhead, K.A.; Perry, K.D. Biocontrol of Invasive Conical Snails by the Parasitoid Fly Sarcophaga villeneuveana in South Australia 20 Years after Release. Insects 2021, 12, 865. https://doi.org/10.3390/ insects12100865

Academic Editors: Gordon Port, Jenna Ross and Rory McDonnell

Received: 25 August 2021

Accepted: 18 September 2021

Published: 24 September 2021

Publisher's Note: MDPI stays neutral with regard to jurisdictional claims in published maps and institutional affiliations.

Copyright: (c) 2021 by the authors. Licensee MDPI, Basel, Switzerland. This article is an open access article distributed under the terms and conditions of the Creative Commons Attribution (CC BY) license (https:// creativecommons.org/licenses/by/ $4.0 /)$.
Simple Summary: Two invasive conical snail species are major pests of pastures and grain crops in Australia. In 2000, a parasitoid fly, Sarcophaga villeneuveana, was sourced from the snails' native Mediterranean range and introduced on the Yorke Peninsula, South Australia, for biological control of the conical snail Cochlicella acuta. The fly successfully established in the region but assessments of the fly's impact in different snail habitats were limited. Twenty years on, four field surveys were performed over two years to measure its geographic spread and parasitism rates on C. acuta and the small pointed snail, C. barbara. In total, $>88,000$ snails were collected using standardised sampling methods to investigate the parasitism of host snails in different habitats. The fly was found at 13 of 19 sampled sites up to $34 \mathrm{~km}$ from nursery release sites. Total parasitism rates of suitably sized snails ( $\geq 5 \mathrm{~mm}$ shell height) were $\approx 3 \%$ for both $C$. acuta and C. barbara. Rates were higher in C. acuta $(5.4 \%)$ and C. barbara $(15.2 \%)$ in exposed habitats above ground level. Parasitism rates up to $48 \%$ in $C$. acuta and $29 \%$ in C. barbara at sites near flowering vegetation suggested that the fly benefits from floral resources.

Abstract: Two conical snail species introduced to Australia from the Mediterranean region during the 20th century are major pests of pastures and grain crops. In 2000, a parasitoid fly, Sarcophaga villeneuveana, was introduced into South Australia for biocontrol of the conical snail, Cochlicella acuta. The fly successfully established in the region but assessments of its impact in different snail aestivation microhabitats were limited. Twenty years on, field surveys were conducted to assess the geographic distribution and parasitism rates of S. villeneuveana on conical snails in the Yorke Peninsula region. Nineteen sites were sampled on four occasions in January and April of both 2019 and 2020. In total, $>85,600$ C. acuta and $>2400$ C. barbara were collected from cryptic (ground or plant refuge) and exposed (open ground or elevated substrate) aestivation habitats and assessed for parasitism. The fly was detected at 13 of 19 sampled sites up to $34 \mathrm{~km}$ from nursery release sites. Total parasitism rates of suitably sized snails ( $\geq 5 \mathrm{~mm}$ shell height) were $2.9 \%$ for $C$. acuta and $3.4 \%$ for C. barbara. Maximum parasitism rates of $48 \%$ for C. acuta and $29 \%$ for C. barbara were found at sites adjacent to spring- and summer-flowering native vegetation. Across 13 sites, parasitism rates were higher for C. acuta (5.4\%) and C. barbara (15.2\%) in exposed habitats above ground level. However, only $34 \%$ of C. acuta and $14 \%$ of C. barbara were found in elevated habitats as most snails were found in cryptic refuges. There was a seasonal decline in abundance of C. acuta $(66 \%)$ and C. barbara $(45 \%)$ between January and April, suggesting natural mortality. Although the overall impact of the fly is limited, high parasitism rates in local environments with flowering resources indicates the potential to enhance biocontrol of both invasive conical snail species.

Keywords: Cochlicella acuta; Cochlicella (Prietocella) barbara; Sarcophaga penicillata 


\section{Introduction}

Four Mediterranean snail species introduced into southern Australia are major pests of pastures and grain crops: the conical snails, Cochlicella acuta (Müller) and Cochlicella (Prietocella) barbara (Linnaeus) (Geomitridae), and the round snails, Theba pisana (Müller) (Helicidae) and Cernuella virgata (da Costa) (Geomitridae) [1,2]. They feed on seedlings in autumn and winter, foul pastures, and contaminate grain harvests by aestivating on the heads, pods and stalks of cereals and legumes [1,2]. All four species have expanded their Australian distributions via human transport and become locally abundant in agricultural areas. The conical snail, C. acuta, was first discovered on Yorke Peninsula (YP) in South Australia in 1953 and the small pointed snail, C. barbara, was first detected in 1921 [1]. Both species have spread across southern and southwestern Australia [3,4].

Integrated management of snails in Australian crops and pastures involves a costly program of molluscicidal baiting, managing crop stubble (e.g., rolling, grazing, cabling, burning) and weed refuges, minimising harvest contamination by snails and postharvest grain cleaning [5]. Conical snails are less susceptible than round snails to most controls due to their more cryptic habits, including a tendency to aestivate in refuges under rocks, logs and inside plants [6], and difficulty in post-harvest separation of snails from physically similar grains [5].

During the 1990s, the Australian Commonwealth Scientific and Industrial Research Organisation (CSIRO) surveyed the native range of Mediterranean pest snails for natural enemies to implement in classical biological control programs [7-12]. Among several species from the dipteran families Sciomyzidae and Sarcophagidae considered as potential biocontrol agents, only Sarcophaga villeneuveana (then known as S. penicillata) (Diptera: Sarcophagidae) displayed sufficient host specificity on pest snails, in particular C. acuta, and was cleared for release in Australia [12,13].

Adult $S$. villeneuveana are active from approximately early spring to mid-autumn. They attack aestivating conical snails $\geq 5 \mathrm{~mm}$ in shell height $[7,14]$. Adults mate within hours after emergence and females are ovoviviparous, depositing a live larva near the shell aperture. The larva crawls inside the shell and feeds on the snail flesh, eventually killing it. After $\approx 7$ days, the larva pupates inside the shell and emerges $\approx 18$ days later as an adult fly [7]. Approximately 5-6 generations are possible during spring and summer [7]. Flies enter diapause in late autumn and overwinter in the pupal stage inside the snail shell.

A classical biological control program targeting C. acuta was initiated in 2000 in South Australia [13] using S. villeneuveana. The fly was collected from the Montpellier region in southern France, imported and mass-reared at the South Australian Research and Development Institute (SARDI). Between 2000 and 2004, >10,000 S. villeneuveana adults were released at 20 sites on the YP and two sites on the Limestone Coast [12,13] (Figure 1). Sequential releases were conducted at four "nursery" sites on the southern YP in the summers of 2002-03 and 2003-04 ( $n \approx 1000-2000$ flies per site) [13]. Single releases were made at additional locations in the summers of 2000-01, 2001-02 and 2003-04 ( $n \approx 200-400$ flies per site) (Figure 1 ).

Subsequent surveys on the Yorke peninsula in 2005, 2007-08 and 2016-17, found that parasitism rates of $C$. acuta were generally $<2 \%$, with a maximum of $17-20 \%$ reported (SARDI, unpub.). These surveys mainly assessed snails $\geq 7 \mathrm{~mm}$ on substrates elevated off the ground (e.g., stubble, fenceposts) and did not include other microhabitats or snails 5-7 mm that are also susceptible to attack [14]. The tendency of conical snails to aestivate in cryptic as well as exposed habitats and higher parasitism rates of elevated snails [7] suggested that overall parasitism rates could have been overestimated in past surveys. Sarcophaga villeneuveana has since been reared from C. barbara collected in Morroco [15] and South Australia (SARDI unpub.), showing that this species is also a suitable host. 


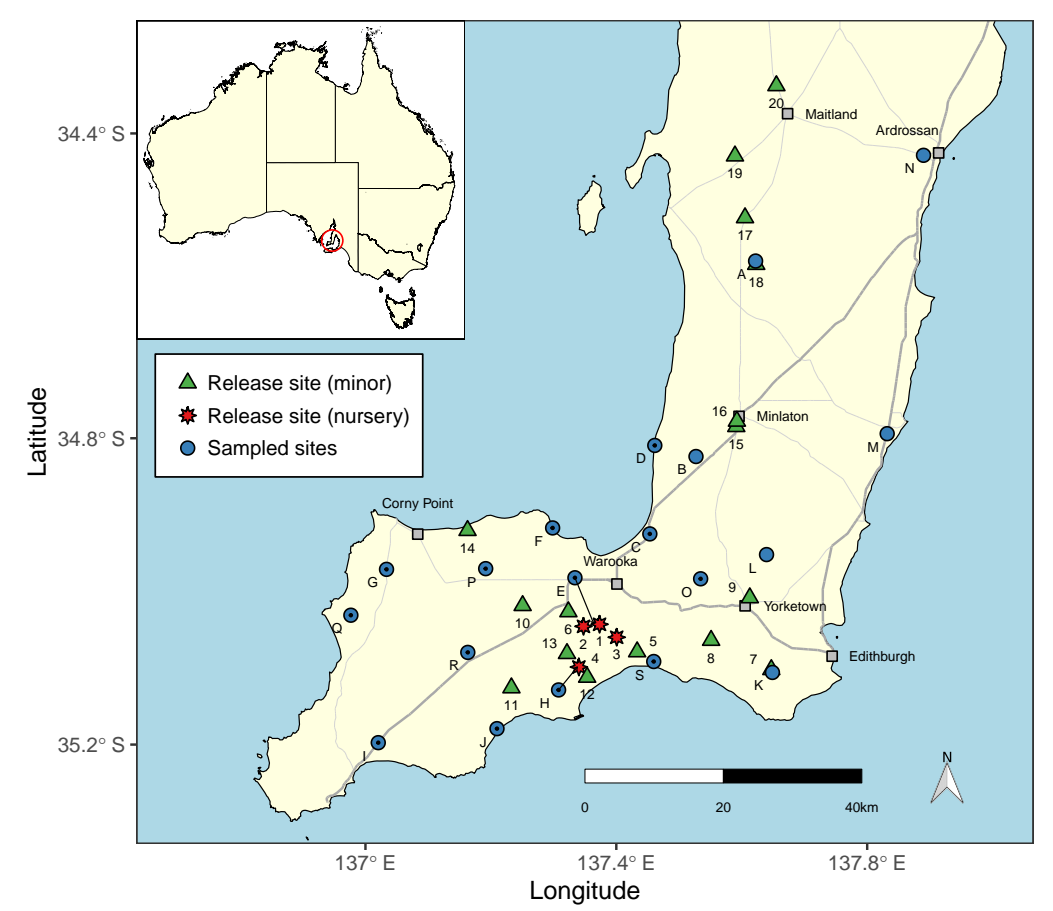

Figure 1. Geographic map of the Yorke Peninsula, South Australia, showing sites where S. villeneuveana was released during 2000-2004 and locations sampled in 2019-2020. Multiple fly releases occurred at nursery sites (red stars) and single releases occurred at minor sites (green triangles). Sites where the fly was present (blue circles with a black dot) or not found (blue circles) are shown.

The aims of this study were to investigate the geographic distribution of S. villeneuveana on the YP and the parasitism rates of suitable C. acuta and C. barbara $(\geq 5 \mathrm{~mm})$ in different microhabitats. Parasitism rates were compared between coexisting populations of C. acuta and C. barbara to assess the relative host suitability of these species for $S$. villeneuveana. Surveys were conducted on the YP in 2019 and 2020 in mid-summer (January) and at the end of the active period of $S$. villeneuveana in autumn (April) to assess temporal changes in parasitism rates. Since conical snails do not breed over summer [6], parasitism rates should increase with successive fly generations throughout their active season. Parasitism was examined in exposed and cryptic snail aestivation microhabitats to determine ecological specialisation of $S$. villeneuveana. This work assessed the impact from the initial fly releases after 20 years and provides baseline data for future attempts to improve biocontrol of conical snails.

\section{Methods}

\subsection{Field Sampling and Data Collection}

Field sampling in agricultural areas on the Yorke Peninsula, South Australia, was conducted on four occasions: 21-24 January and 9-12 April 2019, and 20-23 January and 21-23 April 2020. Fourteen sites were sampled in January 2019 and an additional five (19 in total) were sampled on all subsequent occasions (Figure 1). In April 2020, site K was within an area recently burned by fire and no live snails were found.

Standardised sampling was performed using a belt transect method and timed searches. At each site, four $25 \times 2 \mathrm{~m}$ transects were sampled along roadside verges bordering paddocks with cereals, canola, legumes, or pasture. In each transect, C. acuta and C. barbara of suitable size for parasitism (shell height $\geq 5 \mathrm{~mm}$ from apex to aperture $[7,14]$ ) were collected from four microhabitats: (1) substrates elevated above ground level, such as on plants, stubble and fence posts (elevated); (2) under the base of plants and inside grass tussocks (plant refuge); (3) under refuges at ground level, such as logs and rocks (ground refuge); and (4) within quadrats at ground-level (quadrat). Elevated, plant refuge 
and ground refuge habitats were sampled by searching each transect and nearby areas for a period of five minutes per habitat. A $30 \times 30 \mathrm{~cm}$ quadrat was randomly placed at five-metre intervals in each transect (five quadrats per transect) and all suitable snails were collected. Snails were returned to SARDI laboratories in Adelaide and maintained in plastic containers with mesh lids at $20-24{ }^{\circ} \mathrm{C}, 14$ light $/ 10 \mathrm{~h}$ dark, and $30-40 \%$ relative humidity for at least two weeks to allow flies to emerge. After rearing, snails clearly dead for longer than the rearing period were excluded and the remaining snails were visually examined for evidence of parasitism. Assessments based solely on fly emergence underestimate attack rates and mortality [14]; therefore, evidence of parasitism included the presence of a fly larva or pupa, an open fly pupal case or a fly inside the shell (Tables 1 and 2). Snails not clearly alive or in the above categories were dissected and examined. Parasitism rates were calculated by dividing the number of snails with evidence of parasitism by the total number of suitable snails collected. Snails that died of unknown causes after collection were included in the total.

Table 1. Parasitism by S. villeneuveana of C. acuta on Yorke Peninsula, South Australia, in January and April of 2019 and 2020.

\begin{tabular}{lrrrrr}
\hline & \multicolumn{2}{c}{$\mathbf{2 0 1 9}$} & \multicolumn{2}{c}{$\mathbf{2 0 2 0}$} & \multirow{2}{*}{ Total } \\
\cline { 2 - 5 } & Jan & Apr & Jan & Apr & \\
\hline No. sites with C. acuta & 14 & 19 & 19 & 18 & 19 \\
No. sites with fly detected & 8 & 13 & 13 & 13 & 13 \\
\hline No. suitable snails $>5$ mm & 37,347 & 9512 & 26,888 & 11,926 & 85,673 \\
No. live snails & 36,261 & 8352 & 23,872 & 8252 & 76,737 \\
No. dead snails (unknown) & 597 & 349 & 2499 & 3548 & 6993 \\
No. shells with fly larva & 1 & 15 & 8 & 1 & 25 \\
No. shells with fly pupa & 54 & 55 & 31 & 25 & 165 \\
No. shells with dead fly & 23 & 56 & 35 & 0 & 114 \\
No. shells with open fly pupa & 411 & 685 & 443 & 100 & 1639 \\
No. flies emerged during rearing & 104 & 189 & 69 & 23 & 385 \\
\hline Parasitism rate (all sites) & $1.31 \%$ & $8.53 \%$ & $1.92 \%$ & $1.06 \%$ & $2.27 \%$ \\
Parasitism rate (fly-positive sites) & $1.78 \%$ & $10.72 \%$ & $2.30 \%$ & $1.18 \%$ & $2.85 \%$ \\
\hline
\end{tabular}

Table 2. Parasitism by S. villeneuveana of C. barbara on Yorke Peninsula, South Australia, in January and April of 2019 and 2020.

\begin{tabular}{lrrrrr}
\hline & $\mathbf{2 0 1 9}$ & \multicolumn{2}{c}{$\mathbf{2 0 2 0}$} & \multirow{2}{*}{ Total } \\
\cline { 2 - 5 } & Jan & Apr & Jan & Apr & \\
\hline No. sites with C. barbara & 5 & 9 & 11 & 5 & 11 \\
No. sites with fly detected & 3 & 5 & 7 & 4 & 7 \\
\hline No. suitable snails $>5 \mathrm{~mm}$ & 684 & 698 & 872 & 158 & 2412 \\
No. live snails & 638 & 636 & 820 & 124 & 2218 \\
No. dead snails (unknown) & 41 & 8 & 40 & 32 & 121 \\
No. shells with fly larva & 0 & 1 & 1 & 0 & 2 \\
No. shells with fly pupa & 0 & 5 & 1 & 1 & 7 \\
No. shells with dead fly & 0 & 2 & 2 & 0 & 4 \\
No. shells with open fly pupa & 5 & 46 & 8 & 1 & 60 \\
No. flies emerged during rearing & 1 & 9 & 0 & 0 & 10 \\
\hline Parasitism rate (all sites) & $0.73 \%$ & $7.74 \%$ & $1.38 \%$ & $1.27 \%$ & $3.03 \%$ \\
Parasitism rate (fly-positive sites) & $0.91 \%$ & $8.88 \%$ & $1.39 \%$ & $1.54 \%$ & $3.39 \%$ \\
\hline
\end{tabular}

\subsection{Data Analysis}

Count data from four transects were pooled prior to analysis, providing a single sample from each habitat per site and sampling occasion. Statistical analysis was performed 
using R version 4.0.5 [16] and plots visualised using ggplot2 [17]. Geographic distances between field sites were calculated using R package geosphere version 1.5-10 [18].

Snail abundance and parasitism data were analysed using generalised linear mixed models (GLMM) fitted in R package glmmTMB version 1.1.1 [19]. Data exploration was carried out according to Zuur [20] to select the most appropriate error distribution and best fit models. Initial models included all variables of interest and two-way interactions. Models were evaluated by comparing Akaike's Information Criterion (AIC) values and investigating diagnostics of scaled residuals using R package DHARMa version 0.4.1 [21]. Tests for dispersion and zero-inflation were performed using the DHARMa functions testDispersion and testZeroInflation ( $n=1000$ simulations) and the check_overdispersion function in $\mathrm{R}$ package performance version 0.7 .3 [22]. Significance of main effects was tested using likelihood ratio tests with the anova and drop1 functions in $\mathrm{R}(\alpha=0.05)$. Nonsignificant interactions were dropped to retain the minimum adequate model. The final model fit was checked by visualising plots of scaled residuals against each predictor [20]. Pairwise comparisons were performed using least-squared means with Tukey's adjustment in R package emmeans version 1.6.1 [23].

Snail abundance at 19 sites (540 observations) was analysed using a negative binomial GLMM (family = nbinom1, log link) to test the effects of snail species, habitat and sampling date. Initial models were fitted with snail count as the response variable and snail species, habitat and sampling date, and all two-way interactions, as fixed effects. Site was included as a random effect to model variation in snail abundance among sites and dependency among multiple observations over time at the same sites [20]. The final model included all main effects and an interaction between snail species and sampling date. Additionally, the overall proportions of snails found in different habitats were compared between species using a chi-square $2 \times 4$ contingency table of total abundance $(\alpha=0.05)$.

Parasitism rates of conical snails at 13 sites (360 observations) where the fly was present were analysed using a binomial GLMM with a logit link function. Initial models were fitted with parasitism rate as the response variable and snail species, habitat, sampling date, and all two-way interactions, as fixed effects. Site was included as a random effect (see above). Snail abundance ( $\log$ ) was included as a continuous covariate to investigate the relationship between host population size and parasitism rate. The final model included all fixed effects and the covariate with no interactions. Tests for zero inflation were non-significant; therefore, observation-level random effects were included to correct for over-dispersion in the initial model (dispersion ratio $=7.75$ calculated using the check_overdispersion function) [24].

\section{Results}

\subsection{Abundance of Conical Snails}

In total, 85,673 C. acuta and 2412 C. barbara $\geq 5 \mathrm{~mm}$ were collected in 2019 and 2020 and assessed for parasitism (Tables 1 and 2). C. acuta was found at all 19 sites and C. barbara was found at 11 . Mean snail abundance differed significantly among species $\left(\chi^{2}=524.36, \mathrm{df}=1, p<0.0001\right)$, sampling date $\left(\chi^{2}=83.21, \mathrm{df}=3, p<0.0001\right)$ and habitat $\left(\chi^{2}=72.17, \mathrm{df}=3, p<0.0001\right)$. There was a significant interaction between species and date $\left(\chi^{2}=16.31, \mathrm{df}=3, p<0.001\right)$, indicating that the relationship between snail abundance and date differed between the species.

The mean abundance of $C$. acuta per site and habitat declined significantly between January (mid-summer; 889.2 \pm 207.9 SEM) and April (early autumn; $126.8 \pm 13.7$ ) in 2019 $(t=-10.17, \mathrm{df}=1, p<0.0001)$ and from January $(401.3 \pm 64.3)$ to April $(165.6 \pm 24.7)$ in $2020(t=-2.15, \mathrm{df}=1, p=0.0048)$ (Figure 2). In 2019, total C. acuta abundance declined by $76-88 \%$ in elevated, quadrat and ground refuge habitats (plant refuges were not sampled in January). In 2020, C. acuta abundance declined by $47-75 \%$ in elevated, plant and ground refuge habitats from January to April but increased by $314 \%$ in quadrats (Figure 2). 

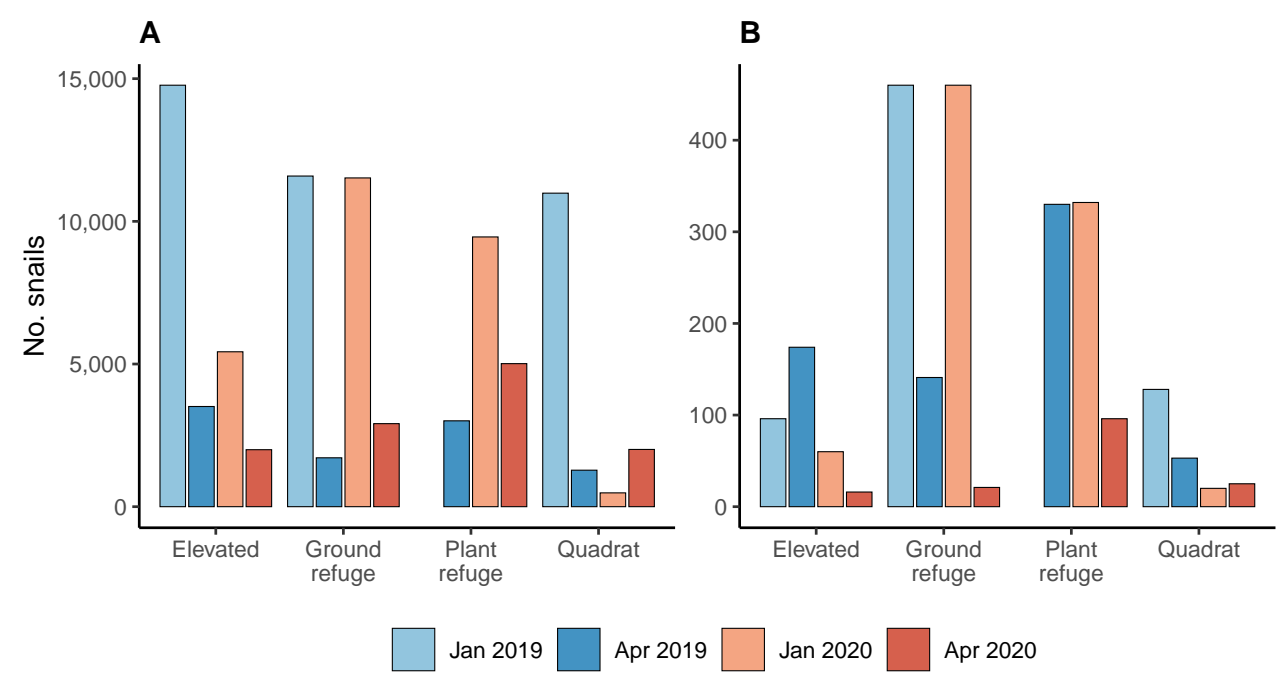

Figure 2. Total numbers of snails collected by habitat and sampling date for: (A) C. acuta at 19 sites ; and (B) C. barbara at 11 sites. Plant refuges were not sampled in January 2019.

The mean abundance of $C$. barbara per site and habitat did not differ between January (45.6 \pm 19.5$)$ and April (25.9 \pm 7.5$)$ in $2019(t=-0.75, \mathrm{df}=1, p=0.878)$, but declined significantly from January $(36.3 \pm 13.7)$ to April $(14.4 \pm 5.2)$ in $2020(t=-2.67, \mathrm{df}=1$, $p=0.037$ ). In 2020, total C. barbara abundance declined by $71-95 \%$ in elevated, ground and plant refuge habitats from January to April but increased by $25 \%$ in quadrats (Figure 2).

Conical snails were more abundant in elevated habitats $(292.7 \pm 75.6)$ than in plant refuges $(243.1 \pm 7.1 ; t=-3.29, \mathrm{df}=1, p=0.006)$ but abundance did not differ between elevated habitats and ground refuges (316.6 $\pm 57.3 ; t=-0.37, \mathrm{df}=1, p=0.983)$. Snails were more abundant in ground refuges than plant refuges $(t=-2.9, \mathrm{df}=1, p=0.019)$ and less abundant in quadrats than all other habitats $(p<0.0001)$ (Figure 2$)$. The proportions of snails found in each habitat differed between species $\left(\chi^{2}=529.35, \mathrm{df}=3, p<0.0001\right)$. In total, $30 \%$ of $C$. acuta were found on elevated substrates, $32.5 \%$ in ground refuges, $20.5 \%$ in plant refuges and $17 \%$ in quadrats. By comparison, $14 \%$ of $C$. barbara were found on elevated substrates, $45 \%$ in ground refuges, $31 \%$ in plant refuges and $9 \%$ in quadrats (Figure 2).

\subsection{Parasitism of Conical Snails by S. villeneuveana}

Sarcophaga villeneuveana was detected at 13 of 19 sites and was restricted to the southern "foot" of the Yorke Peninsula (Figures 1 and 3). The fly parasitised C. acuta at 13 of 19 sites and C. barbara at 7 of 11 , at distances up to $34 \mathrm{~km}$ from nursery release sites (site $\mathrm{Q} /$ release site 4) and $21 \mathrm{~km}$ from minor release sites (site Q/release site 14) (Figure 3).

Parasitism rates across both years were $2.27 \%$ for C. acuta and 3.03\% for C. barbara at 19 sites, and $2.85 \%$ and $3.46 \%$, respectively, at 13 sites where the fly was found (Tables 1 and 2). The highest total parasitism rate at an individual site across all sampling occasions was $10.7 \%$ for C. acuta (site J) and $12.4 \%$ for C. barbara (site R) (Figure 3). The maximum parasitism rate at any single site and sampling occasion was $48.3 \%$ for $C$. acuta and $29.6 \%$ for $C$. barbara at site J in April 2019 (Figure 3).

Parasitism rates differed significantly among snail species $\left(\chi^{2}=13.78, \mathrm{df}=1\right.$, $p=0.0002)$, sampling date $\left(\chi^{2}=19.89, \mathrm{df}=3, p=0.0001\right)$ and habitat $\left(\chi^{2}=60.21\right.$, $\mathrm{df}=3, p<0.0001$ ). Snail abundance was a significant co-variate (estimate $=-0.59 \pm 0.11$, $p<0.0001$ ), implying a negative relationship between snail abundance and parasitism rate.

Parasitism rates of conical snails did not differ between years in the month of January $(t=0.89, \mathrm{df}=1, p=0.809)$, but were significantly different in April $(t=21.92, \mathrm{df}=1$, $p<0.0001)$. In 2019, parasitism increased from January (1.3\%) to April $(8.5 \%)(t=12.15$, $\mathrm{df}=1, p<0.0001)$ but in 2020 there was a decline from January $(1.9 \%)$ to April $(1.1 \%)$ $(t=-8.27, \mathrm{df}=1, p<0.0001)$. 
A

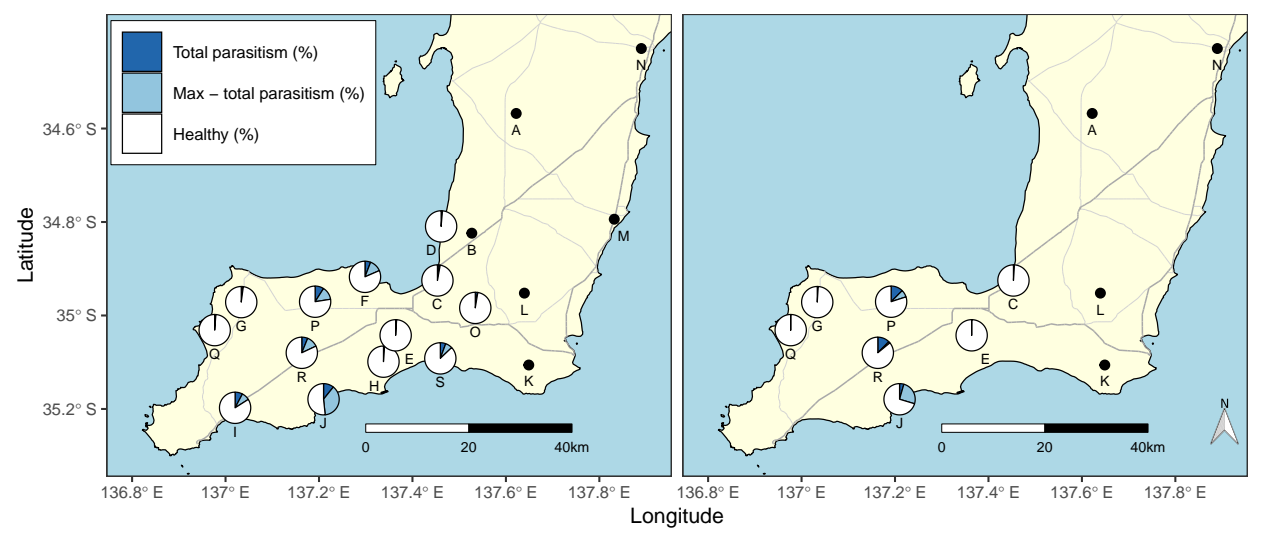

Figure 3. Geographic map of the Yorke Peninsula, South Australia, showing S. villeneuveana parasitism rates on: (A) C. acuta at 19 sites; and (B) C. barbara at 11 sites. Pies display the total parasitism rate across all sampling dates (dark blue) and the maximum parasitism rate on any single sampling date (light blue and dark blue) at sites where the fly was present. Black dots represent sites where snails were collected but $S$. villeneuveana was not recovered.

Parasitism rates were higher in conical snails on elevated substrates $(5.5 \%)$ than in ground refuges $(0.9 \%)(t=6.93, \mathrm{df}=1, p<0.0001)$, plant refuges $(2.5 \%)(t=4.32, \mathrm{df}=1$, $p<0.0001)$, or quadrats $(1.3 \%)(t=6.33, \mathrm{df}=1, p<0.0001)$ (Figure 4$)$. No difference in parasitism was found among the other habitats. In elevated substrates, the total parasitism rate was $5.4 \%(n=23,413)$ for C. acuta and $15.2 \%(n=302)$ for C. barbara (Figure 4$)$.

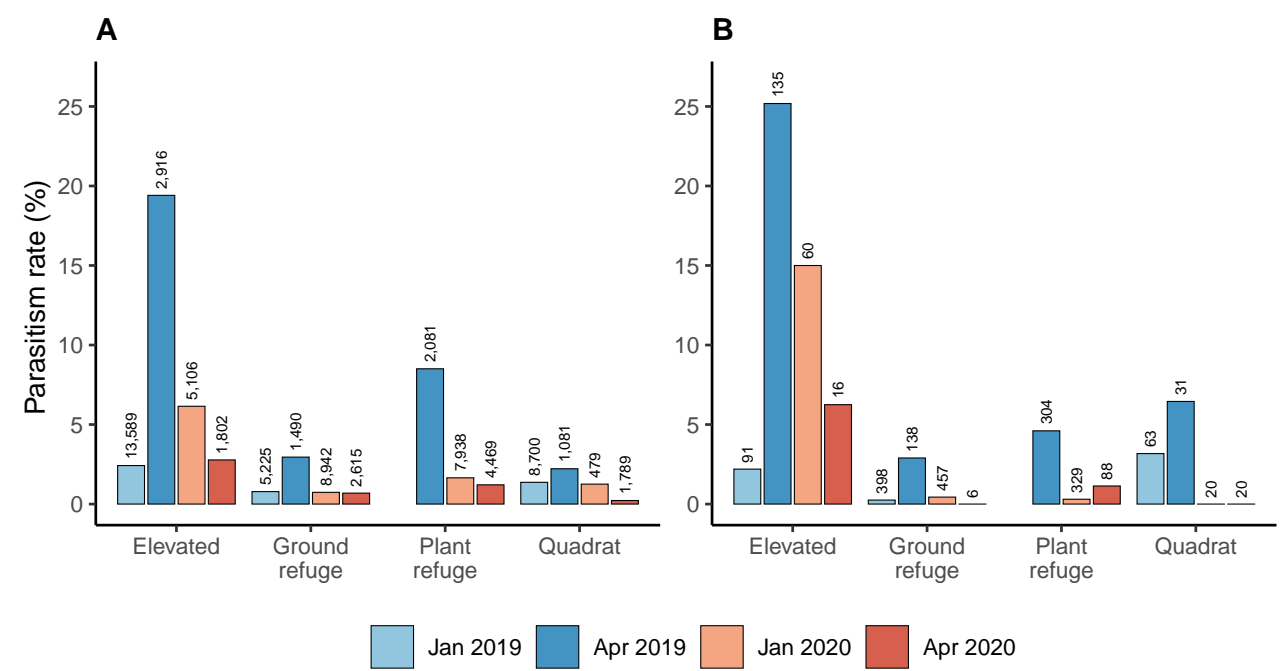

Figure 4. Total S. villeneuveana parasitism rates on: (A) C. acuta at 13 sites; and (B) C. barbara at 7 sites, by habitat and sampling date, with snail sample size shown above bars. Plant refuges were not sampled in January 2019.

\section{Discussion}

Successful biological control remains a priority for integrated management of invasive snails in Australia. To our knowledge, Sarcophaga villeneuveana is the only dipteran parasitoid implemented in a classical biocontrol program for terrestrial snail pests worldwide. We assessed the establishment and spread of S. villeneuveana 20 years after its introduction to Australia and investigated parasitism rates of conical snails in different aestivation microhabitats.

Sarcophaga villeneuveana has established on the southern Yorke Peninsula and dispersed at least $34 \mathrm{~km}$ from nursery sites where multiple fly releases were conducted 
from 2000-2004 [13]. The fly was not found in northern YP where low numbers of flies $(n \approx 200$ per site) were released on a single occasion. Initial surveys found a lower abundance of host conical snail populations in northern than in southern areas of the peninsula. Low populations and patchy distributions of host snails may have contributed to unsuccessful northern establishment of the fly.

The number of insects released in biological control programs can be critical for agent establishment $[25,26]$. The release of 1000 individuals has often been used as a guideline as the minimum release size for parasitoids, but establishment may be achieved with continuous releases of smaller numbers at several sites [27]. Leyson et al. [13] cited some difficulty rearing the parasitoid in large numbers in the laboratory, and subsequent surveys conducted 2-14 months after release did not recover the fly near Minlaton where only 200 individuals were released. In contrast, the fly was recovered within seven months after multiple releases of 300-400 per release at nursery sites near Warooka. The relatively close proximity of the four nursery sites $(2-7 \mathrm{~km})$ may also have contributed to successful establishment.

Overall S. villeneuveana parasitism of C. acuta was low (2.9\%) across sites where the fly exists. These rates are similar to those found on the YP in 2005, 2007-08 and 2016-17 (SARDI, unpub.) and slightly less than reported in southern France (4\%) from where the flies were originally sourced $[7,13]$. In contrast, parasitism rates of $13-25 \%$ were recorded for S. villeneuveana attacking C. acuta in southern Spain and southern Portugal [14]. Evidence for a negative relationship between snail abundance and parasitism rates requires further investigation. This result could be influenced by a small number of sites with high snail but low fly abundance in our dataset. For example, site $\mathrm{E}$ had the largest snail population ( $n=23,741$ conical snails collected) but a parasitism rate of only $0.1 \%$. It seems unlikely that increased host abundance alone could inhibit fly performance, but other environmental factors may limit their ability to exploit high prey numbers in some locations.

Cochicella barbara was found to be a suitable host for S. villeneuveana, as previously reported in Europe [9]. A larger proportion of C. barbara were found aestivating in cryptic habitats than C. acuta, implying some differences in host behaviour and susceptibility to fly attack between the snail species (albeit samples sizes of $C$. barbara were much smaller). Parasitism rates were slightly higher in C. barbara than C. acuta despite smaller population sizes and a more restricted distribution on the YP. Sarcophaga villeneuveana attacked both snail hosts at multiple sites where $C$. acuta was the predominant species. This is an interesting finding given the smaller size of $C$. barbara. Previous studies found that larger $C$. acuta were more likely to be parasitised by $S$. villeneuveana $[7,9]$, suggesting that the fly has a preference for larger snails or they are more suitable for development. Likewise, more flies emerged from snails in southern Iberia during spring when a greater proportion of large snails $(>10 \mathrm{~mm})$ were collected [14]. However, a greater proportion of smaller snails $(6-10 \mathrm{~mm})$ were parasitised in summer and autumn, implying that $S$. villeneuveana host usage may depend on host availability [14].

Cochlicella acuta in Australia belong to a genetic lineage derived from southern Iberia (Spain and Portugal) and Morocco [28]. Two common S. villeneuveana CO1 haplotypes from southern Portugal, Spain and Morocco are not known to occur in Australian flies, which were sourced from the Montpellier region in France [29]. Due to different geographic sources of the fly and snail hosts, it was argued that a genetic mismatch may have contributed to low parasitism success of S. villeneuveana in Australia [28,29].

Our study showed that $S$. villeneuveana sourced from France can perform well against conical snails in localised areas of southern Australia. Parasitism rates up to $48 \%$ for C. acuta and $29 \%$ for C. barbara were observed at sites adjacent to spring- and summer-flowering native vegetation. Nil or low parasitism was observed at locations lacking such vegetation (for example, at site E), which is common in southern Australian broad-acre farming. The success of $S$. villeneuveana in attacking conical snails may depend on the availability of floral resources. In parasitoids, consuming nectar and pollen enhances adult fitness and prolongs lifespan [30-33]. Carbohydrate-based diets with lipids and protein (e.g., pollen 
and nectar) maximised the lifespan and egg load of the flesh fly, Sarcophaga crassipalpis [34]. Thus, selecting release sites with native vegetation flowering when flies are active may enhance establishment and parasitism. Local resources may also prevent the fly from dispersing too rapidly in search of food, thereby increasing the likelihood of mating and the time spent searching for hosts [35,36]. Even a modest boost in parasitism rates soon after fly emergence in early spring may compound across successive fly generations and increase overall parasitism rates by autumn.

Parasitism increased from mid-summer to early autumn in 2019, which was expected as successive fly generations attack aestivating C. acuta. This snail has a mostly biennial life cycle in southern Australia and does not breed during summer [6]. However, no seasonal increase in parasitism was observed in 2020. Sampling during 21-23 April 2020 followed a rain event of $\approx 7 \mathrm{~mm}$ on 19 April 2020. Rainfall increased snail activity on the soil surface, as shown by an increase in quadrat counts as C. acuta and C. barbara exited aestivation habitats (Figure 2). It is possible that more snails were sampled as they emerged from cryptic habitats, where they are less susceptible to attack, reducing estimated parasitism.

The presence of host snails alone does not ensure establishment of $S$. villeneuveana following releases, or parasitism rates sufficient to suppress conical snail pests. Snails on elevated substrates were parasitised at higher rates than other habitats, as previously reported [7]. However, $53 \%$ of C. acuta and $76 \%$ of C. barbara aestivated in ground or plant refuges (Figure 2), suggesting these snails prefer cryptic habitats. Conical snails were observed inhabiting elevated substrates (e.g., fence posts and stubble) only when ground level refuges (plants, grasses, rocks) were unavailable. The fly is less successful attacking snails sheltering on the ground or in refuges, so reducing cryptic refuges (e.g., by controlling weeds, removing rocks and other objects) may increase parasitism as well as expose them to potentially lethal temperatures. A large decline in the abundance of live snails between January and April could reflect mortality from extreme summer heat or death of mature snails at the end of their life cycle [6]. Likewise, releasing S. villeneuveana near remnant patches of flowering native vegetation could provide it with food resources and shelter from heat and wind extremes.

\section{Conclusions}

The impact of the biological control agent, S. villeneuveana, on populations of invasive conical snails in South Australia after 20 years is limited. Factors inhibiting success may include single-fly releases with relatively few individuals, variation in abundance and distribution of host snails, cryptic snail aestivation habitats that are inaccessible to flies, a lack of floral resources for flies in agricultural areas, the use of broad-spectrum insecticides on farms that are harmful to flies, possible genetic or ecological differences between host and parasitoid populations [28,29], or a loss of genetic variability due to laboratory inbreeding $[37,38]$. However, evidence of substantially higher parasitism in localised environments with favourable habitat for the fly indicates the potential to improve biological control of both conical snail species. Habitat manipulation, such as the removal of snail refuges and the promotion of vegetation strips to provide floral resources for flies during spring and summer, may enhance biological control. Furthermore, S. villeneuveana attacks C. barbara at similar rates to $C$. acuta, making it suitable for release in regions where either species is a pest.

Author Contributions: Conceptualization, methodology, investigation, data curation, formal analysis, writing —original draft preparation, writing — review and editing, supervision, K.A.M. and K.D.P.; visualization, project administration, funding acquisition, K.D.P.; All authors have read and agreed to the published version of the manuscript.

Funding: This research was funded by the Grains Research and Development Corporation and the South Australian Research and Development Institute, grant number DAS1903-009BLX (9177340).

Data Availability Statement: The data presented in this study are available on request from the corresponding authors. 
Acknowledgments: The authors thank Nicole Fechner, Helen Brodie, Greg Baker, Kate Ballard, Lamyaa Alwash, Humayra Akter, Rebecca Hamdorf, Kate Ballard and Valerie Caron for assistance with field sampling and examining snails.

Conflicts of Interest: The authors declare no conflict of interest. The funders had no role in the design of the study; in the collection, analyses, or interpretation of data; in the writing of the manuscript, or in the decision to publish the results.

\section{References}

1. Baker, G.H. The Biology and Control of White Snails (Mollusca: Helicidae), Introduced Pests in Australia; CSIRO: Melbourne, Australia, 1986. [CrossRef]

2. Baker, G.H. The population dynamics of the Mediterranean snails Cernuella virgata, Cochlicella acuta (Hygromiidae) and Theba pisana (Helicidae) in pasture-cereal rotations in South Australia: A 20-year study. Aust. J. Exp. Agric. 2008, 48, $1514-1522$. [CrossRef]

3. Atlas of Living Australia Website. Species Page, Cochlicella acuta. Available online: https://bie.ala.org.au/species/urn:lsid: biodiversity.org.au:afd.taxon:1996efa6-2db2-424f-a822-555e2d67cdc5 (accessed on 21 August 2021).

4. Atlas of Living Australia Website. Species Page, Prietocella barbara. Available online: https://bie.ala.org.au/species/urn:lsid: biodiversity.org.au:afd.taxon:e9ba197e-e04d-4a5c-9b58-9ccdcb20d4c5 (accessed on 21 August 2021).

5. Leonard, E.; Hopkins, D.C.; Baker, G.H. (Eds.) Bash Em Burn Em Bait Em: Integrated Snail Managament in Crops and Pastures; South Australian Research and Development Institute: Adelaide, Australia, 2003.

6. Baker, G.H.; Hawke, B.G.; Vogelzang, B.K. Life history and population dynamics of Cochlicella acuta (Müller) (Gastropoda: Helicidae) in a pasture-cereal rotation. J. Molluscan. Stud. 1991, 57, 259-266. [CrossRef]

7. Coupland, J.B.; Baker, G.H. Host distribution, larviposition behaviour and generation time of Sarcophaga penicillata (Diptera: Sarcophagidae), a parasitoid of conical snails. B Entomol. Res. 1994, 84, 185-189. [CrossRef]

8. Coupland, J.B.; Espiau, A.; Baker, G.H. Seasonality, longevity and infection efficiency of Salticella fasciata (Diptera, Sciomyzidae), a candidate for the biological control of pest helicid snails. Biol. Control 1994, 4, 32-37. [CrossRef]

9. Coupland, J.B. Diptera associated with snails collected in south-western and west-Mediterranean Europe. Vertigo 1994, 3, 19-26.

10. Coupland, J.B.; Baker, G.H. The potential of several species of terrestrial Sciomyzidae as biological control agents of pest helicid snails in Australia. Crop. Prot. 1995, 14, 573-576. [CrossRef]

11. Coupland, J.B. Influence of snail feces and mucus on oviposition and larval behavior of Pherbellia cinerella (Diptera: Sciomyzidae). J. Chem. Ecol. 1996, 22, 183-189. [CrossRef]

12. Coupland, J.B.; Baker, G.H. Search for biological control agents of invasive Mediterranean snails. In Biological Control: A Global Perspective; CABI: Wallingford, UK, 2007; pp. 7-12. [CrossRef]

13. Leyson, M.; Hopkins, D.C.; Charwat, S. Release and establishment in South Australia of Sarcophaga penicillata (Diptera: Sarcophagidae), a biological control agent for Cochlicella acuta (Mollusca: Hygromiidae). In Slugs $\mathcal{E}$ Snails: Veterinary $\mathcal{E}$ Environmental Perspectives, BCPC Symposium Proceedings No. 80; Dussart G.B.J., Ed.; British Crop Protection Council: Farnham, UK, 2003; pp. 295-300.

14. Thomann, T.; Jourdan, M.; Richet, R.; Sheppard, A.; Baker, G.H. Parasitism of the conical snail, Cochlicella acuta, by the fly, Sarcophaga villeneuveana, in south-western Europe. BioControl 2020, 65, 673-679. [CrossRef]

15. Fendane, Y.; Richet, R.; Thomann, T.; Jourdan, M.; Baker, G.; Ghamizi, M.; Sheppard, A. First records of flesh flies (Diptera: Sarcophagidae) emerging from terrestrial snails in Morocco. Afr. Entomol. 2018, 26, 124-130. [CrossRef]

16. R Core Team. R: A Language and Environment for Statistical Computing; R Foundation for Statistical Computing: Vienna, Austria, 2021.

17. Wickham, H. ggplot2: Elegant Graphics for Data Analysis; Springer: New York, NY, USA, 2016.

18. Hijmans, R.J. geosphere: Spherical Trigonometry. R Package Version 1.5-10, 2019. Available online: https://CRAN.R-project.org/ package $=$ geosphere (accessed on 21 August 2021).

19. Brooks, M.E.; Kristensen, K.; van Benthem, K.J.; Magnusson, A.; Berg, C.W.; Nielsen, A.; Skaug, H.J.; Maechler, M.; Bolker, B.M. glmmTMB balances speed and flexibility among packages for zero-inflated generalized linear mixed modeling. $R$ J. 2017, 9, 378-400. [CrossRef]

20. Zuur, A.F.; Ieno, E.N. A protocol for conducting and presenting results of regression-type analyses. Methods Ecol. Evol. 2016, 7, 636-645. [CrossRef]

21. Hartig, F. DHARMa: Residual Diagnostics for Hierarchical (Multi-Level / Mixed) Regression Models. R Package Version 0.4.1, 2021. Available online: https://CRAN.R-project.org/package=DHARMa (accessed on 21 August 2021).

22. Fox, J.; Weisberg, S. An R companion to applied regression. J. Open Source Softw. 2019, 6, 3139. [CrossRef]

23. Lenth, R.V. emmeans: Estimated Marginal Means, aka Least-Squares Means. R Package Version 1.6.1, 2021. Available online: https:/ /CRAN.R-project.org/package=emmeans (accessed on 21 August 2021).

24. Harrison, X.A. A comparison of observation-level random effect and beta-binomial models for modelling overdispersion in binomial data in ecology \& evolution. PeerJ 2015, 3, e1114. [CrossRef] [PubMed]

25. Grevstad, F.S. Factors influencing the chance of population establishment: Implications for release strategies in biocontrol. Ecol. Appl. 1999, 9, 1439-1447. [CrossRef] 
26. Possingham, H.; Shea, M. Optimal release strategies for biological agents: An application of stochastic dynamic programming to population management. J. Appl. Ecol. 2000, 37, 77-86. [CrossRef]

27. Hopper, K.R.; Roush, R.T. Mate finding, dispersal, number released, and the success of biological control introductions. Ecol. Entomol. 1993, 18, 321-331. [CrossRef]

28. Jourdan, M.; Thomann, T.; Kriticos, D.J.; Bon, M.C.; Sheppard, A.; Baker, G.H. Sourcing effective biological control agents of conical snails, Cochlicella acuta, in Europe and north Africa for release in southern Australia. Biol. Control 2019, 134, 1-14. [CrossRef]

29. Jourdan, M.; Thomann, T.; Richet, R.; Fendane, Y.; Ghamizi, M.; Bon, M.C.; Sheppard, A.; Baker, G.H. Genetic variability in the parasitic fly, Sarcophaga villeneuveana, in south-western Europe and Morocco. BioControl 2020, 65, 59-70. [CrossRef]

30. Quicke, D.L.J. Parasitic wasps; Chapman \& Hall: London, UK, 1997.

31. Olson, D.M.; Takasu, K.; Lewis, W.J. Food needs of adult parasitoids: Behavioral adaptations and consequences. In Plant-Provided Food for Carnivorous Insects: A Protective Mutualism and Its Applications; Wäckers, F.L., van Rijn, P.C.J., Bruin, J., Eds.; Cambridge University Press: Cambridge, UK, 2005; pp. 137-147. [CrossRef]

32. Jervis, M.A.; Ellers, J.; Harvey, J.A. Resource acquisition, allocation, and utilization in parasitoid reproductive strategies. Annu. Rev. Entomol. 2008, 53, 361-385. [CrossRef]

33. Collatz, J.; Romeis, J. Flowers and fruits prolong survival of Drosophila pupal parasitoids. J. Appl. Entomol. 2021. [CrossRef]

34. Hawley, J.; Simpson, S.J.; Wilder, S.M. Flesh flies regulate the consumption of 3 macronutrients to maximize lifespan and egg production. Behav. Ecol. 2016, 27, 245-251. [CrossRef]

35. Hein, S.; Dorn, S. The parasitoid of a fruit moth caterpillar utilizes fruit components as nutrient source to increase its longevity and fertility. Biol. Control 2008, 44, 341-348. [CrossRef]

36. Tschumi, M.; Albrecht, M.; Collatz, J.; Dubsky, V.; Entling, M.H.; Najar-Rodriguez, A.J.; Jacot, K. Tailored flower strips promote natural enemy biodiversity and pest control in potato crops. J. Appl. Ecol. 2016, 53, 1169-1176. [CrossRef]

37. Gilchrist, A.S.; Cameron, E.C.; Sved, J.A.; Meats, A.W. Genetic consequences of domestication and mass rearing of pest fruit fly Bactrocera tryoni (Diptera: Tephritidae). J. Econ. Entomol. 2012, 105, 1051-1056. [CrossRef] [PubMed]

38. Francuski, L.; Djurakic, M.; Ludoški, J.; Hurtado, P.; Pérez-Bañón, C.; Ståhls, G.; Rojo, S.; Milankov, V. Shift in phenotypic variation coupled with rapid loss of genetic diversity in captive populations of Eristalis tenax (Diptera: Syrphidae): Consequences for rearing and potential commercial use. J. Econ. Entomol. 2014, 107, 821-832. [CrossRef] 